\title{
Correction to: A new primer construction technique that effectively increases amplification of rare mutant templates in samples
}

\author{
Jr-Kai Huang ${ }^{1}$, Ling Fan², Tao-Yeuan Wang ${ }^{1}$ and Pao-Shu Wu ${ }^{1,3^{*}}$
}

\section{Correction to: BMC Biotechnol (2019) 19:62 https://doi.org/10.1186/s12896-019-0555-1}

Following publication of the original article [1], the author informed us that the legend for Fig. 2 was incorrect.

Fig. 2 legend has been corrected in the original article.

The correct legend for Fig. 2 is given below:

Mutant sequence enrichment using stuntmer PCR. The abilities of stuntmers to detect four different mutation scenarios (single nucleotide mutation, two different single nucleotide mutations, and a deletion mutation) were tested under three different sample conditions (only wild-type, 90:10 ratio of wild-type:mutant, and 99:1 ratio of wild-type:mutant). In all cases, the stuntmers were able to detect the mutations even when the mutant templates were present in only $1 \%$ of the tested samples. The wild-type template was completely inhibited in the T790 M point mutation (a) and exon 19 deletion mutation (b). The arrow indicates where the deletion mutation occurred

\section{Author details}

${ }^{1}$ Department of Pathology, Mackay Memorial Hospital, Taipei, Taiwan. 2Department of Nuclear Medicine, Chang Gung Memorial Hospital, Taoyuan,

Taiwan. ${ }^{3}$ Mackay Junior College of Medicine, Nursing, and Management,

Taipei, Taiwan

Published online: 12 November 2019

\section{Reference}

\footnotetext{
1. Huang JK, et al. A new primer construction technique that effectively

increases amplification of rare mutant templates in samples. BMC

Biotechnol. 2019;19:62. https://doi.org/10.1186/s12896-019-0555-1.
}

\footnotetext{
* Correspondence: pw2136@gmail.com

${ }^{1}$ Department of Pathology, Mackay Memorial Hospital, Taipei, Taiwan

${ }^{3}$ Mackay Junior College of Medicine, Nursing, and Management, Taipei,

Taiwan

Full list of author information is available at the end of the article
}

(c) The Author(s). 2019 Open Access This article is distributed under the terms of the Creative Commons Attribution 4.0 International License (http://creativecommons.org/licenses/by/4.0/), which permits unrestricted use, distribution, and reproduction in any medium, provided you give appropriate credit to the original author(s) and the source, provide a link to the Creative Commons license, and indicate if changes were made. The Creative Commons Public Domain Dedication waiver (http://creativecommons.org/publicdomain/zero/1.0/) applies to the data made available in this article, unless otherwise stated. 